\title{
Research on Empirical Evidence for Individualization of Gender Roles across Generations in China
}

\author{
Shuying Huang ${ }^{1 *}$

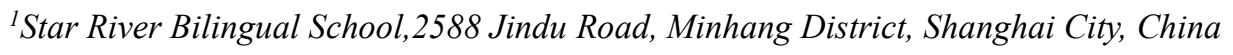 \\ suesyshuyinghuang@outlook.com
}

\begin{abstract}
This study aims to understand the trends in perceptions, preferences, and choices of gender roles among Chinese women born in different generations during the process of modernization and westernization. Individualization theory predicts that as industrialization progresses, traditional moral and social responsibilities shift from social values and family obligations to individual judgments and decisions. We predict that in modern China, while gender equality and feminist consciousness are more prominent, women are more explicitly supportive of gender rights and equality in terms of stereotypical expectations and family role assignments. However, we also predict that implicit perceptions and stereotypes still exist in the form of individual choices and social judgments. In a study comparing the attitudes of men $(\mathrm{N}=210)$ and women $(\mathrm{N}=249)$ born over a fifty-year period (from 60' to $00^{\prime}$ ) toward marital responsibilities and personal choices of daily activities, we found that, consistent with our predictions, younger women showed significantly higher explicit support and preference for daily activities that violate traditional gender stereotypes compared to men. However, their judgments of women who openly violate gender expectations in their marriages did not increase, and their personal choices of daily activities were consistent with gender stereotypical role assignments.
\end{abstract}

Keywords: Gender role, Individualization theory, Role assignment

\section{INTRODUCTION}

Gender studies have traditionally been the focus of scholarly research attention. With the Industrial Revolution, the division of labor in society has changed dramatically, and women have gradually moved from domestic service to social work. With the continuous progress of economic development and society, gender theory has been pushed to new hot spots, and feminism and individualization theory have become new topic center of concern for scholars and the public.

\section{THEORETICAL BASIS OF GENDER ROLES}

\subsection{Gender Role Attitudes}

Gender role attitudes, also known as social gender role attitudes, are based on the concept of gender roles. The concept of gender roles is based on the concept of feminism with equal rights as the core and the concept of roles with masculinity and femininity as the core, and refers to a set of behavioral patterns and norms of responsibility developed by society based on different biological sexes to determine their biological identity status. Gender roles and attitudes, as an important concept related to gender, have always been a hot issue in gender studies, including its perception and understanding of the center of gravity in the lives of both genders and the working ability of both genders, which refers to people's perceptions and attitudes towards the equality of both genders in behavior, activities and tasks. There are two main aspects in the study of gender roles and attitudes: first, the psychological study of the qualities and personalities of men and women, and the reasons for the differences in individual gender roles and attitudes; second, the social analysis of conflicts and pressures on women's gender roles and attitudes caused by the gender division of labor in modern society from the female perspective, and the promotion of equality between men and women in terms of social status and social division of labor. According to the gender role attitude measurement scale developed by Renmin University of China, this study classifies women's gender role attitudes into the following dimensions, including women's awareness of gender equality in the dimensions of family 
and career, ability traits, self-worth, labor and employment, and family division of labor.

\subsection{Modern Theories of Gender Role Attitudes}

Since the Industrial Revolution, the division of labour in society has changed dramatically, giving women, who were previously confined to the home, the opportunity to participate in the social division of labour; however, due to the constraints of traditional attitudes, there is a deeprooted belief that women should work in the home, which has led to and entrenched inequalities in the division of labour, the allocation of rights and the social status of women. Gender discrimination in the labour market results in significant differences between women and men in the choice of occupation, wages and career advancement in the labour market. In the division of labour in the family, domestic work is considered to be the woman's rightful responsibility, and unpaid domestic work leads to the hidden exploitation of a large number of women in the family.

The persistent oppression of women led to the explosion of the feminist movement in the 1960s. During this movement, gender theory was developed, which argues that different gender attitudes and behaviors are socially and culturally constructed rather than rooted in biological differences, and advocates an evolutionary perspective on gender, encouraging women to break free from the constraints of role norms to achieve self-worth. This theory has gradually developed into a valid analytical category in Western academic research and has been applied in the formulation of many public policies.

The concept of gender role attitudes is derived from gender theory and is used to examine an individual's understanding and expectations of gender roles. As society modernizes, gender role attitudes change, and modernization theory of gender role attitudes is born in the context of modernization. Modernization theory was first developed in the United States, and "modernization" can be regarded as a "form of civilization" in line with the characteristics of the history and times, and different scholars have commented on "modernization" from both macro and micro perspectives. "It is interpreted by focusing on institutions at the macro level and individuals at the micro level. In "The Modernization of Man", Ingres distinguishes between "traditional" and "modern" human beings according to the perspective of the "modernization of man", which aims to emphasize individualistic values, the primacy of reason and the praise of professionalism. $"$.

Ten aspects such as willingness to accept new ideas, respect for knowledge, importance of education, punctuality and effectiveness are regarded as the basic characteristics of the "modern man", while obedience to authority, low level of education and conservatism are classified as the characteristics of the "traditional man".
Anthony (2000) studied gender role attitudes by combining modernization theory and the characteristics of "human modernization", and based on the "fractured" characteristics of social modernization, he distinguished two types of gender role attitudes in modern society: one is the traditional type, and the other is the traditional type. The second is the modern gender role attitude, which emphasizes the equality of men and women in education, employment and political status, advocates judging the value of individuals by their abilities and achievements, which encourages women to pursue their personal dreams and dreams. Spiritual independence. The modernization of women's gender roles will encourage women to move from the private to the public sphere, but this does not mean that women have completely abandoned their responsibilities in the private sphere.

\section{AN OVERVIEW OF MODERN CHINESE WOMEN'S "INDIVIDUALIZATION" STUDIES}

In Women and Family in contemporary urban China; Contested female individualization (2013), Bøe discussed the individualization of China's younger generation of women (in this case, women in their twenties and thirties in Beijing), who she claims are "undergoing an individualization transformation in Chinese society."[1] As the first generation of "only child" who grew up in the era of reform and the one-child policy, they have given "a wider range of alternative biographies and greater freedom of self-expression," as well as tremendous pressure to fulfill filial duties to parents and family, both morally and financially, and the traditional values of children being filial to the elderly and women contributing to the family are still prevalent. In conclusion, the individualization for the contemporary urban Chinese female is more than something that is simple and unidirectional, with the recent changes in China which leads to the unique way of the Chinese individualization.

In Cai et al. (2020), the authors discuss about the changes of the values, psychologies and behaviors of the Chinese people over the past half century.[2] Couple types of research methods are mentioned and discussed in the paper, as the three most common types are the "cross time comparison", "intergenerational comparison", and "historical reconstruction". The researchers had three stages with the ideas around traditionality and modernity of the Chinese people which at first traditionality is oppose to modernity, as traditionality is seen to be declined as modernity rises; at the second stage, traditionality and modernity is no longer the two extreme opposite poles on the same spectrum but two independent dimensions, and each dimension contains multiple sub dimensions of different domains; for the third stage the researchers found out that the traditionality and modernity can no longer and not enough to be the 
measure of the modern society and its modernity. Take the reform and opening as a year of division, there is a big shift of the values around idea of traditionality and modernity between the generations born before it and after it, as the authors compare open-to-change, conservation, self-enhancement, self-transcendence between people as four basic values of people (Schwartz, 1994, 1997). [3]For the changes of the personalities of the Chinese people, the researchers combined The Big Five Structure with Chinese Personality Assessment Scale (Weizhen Song, 1993) as the comparison of neuroticism, extroversion, openness, agreeableness, conscientiousness, reliability, individuality, leadership and interpersonal relationship of the Chinese people.[4] In general, the individuality rises amongst the younger generations while the values that considered as traditionality do not fade away but co-exists with the other values in the big picture of complex environment as Chinese society has experienced and is still experiencing a great transformation from tradition to modernity in the past half century.

Zheng (2012) pointed out in book chapter "Chinese women and feminism" that, as women in the old China is completely oppressed under the patriarchal society, the first wave of the Chinese feminism and women's liberation is different from the western feminism theories as it was first brought up by the Chinese male revolutionaries, nationalists and intellectuals for the purpose of warring; after 1949, the CCP government started the women's equality movement, also with the purpose of using the women as labor forces for the people's commune, meanwhile the leaders for this movement are also mostly consisted with male intellectuals and party leaders. [5]

Bøe concluded the theory about the individualization of the 20s and 30s urban contemporary Chinese women as she defines it as "a compulsory condition of modernity", by living in Beijing and having reviews and observations with Chinese women. She concluded that individualization is not unified, must be understood from a perspective sensitive of gender and life stage specific experiences under the complicated and unique changes that China has experienced during the recent 30 years. With what she didn't study and explain clear enough about, the modernity and what it brought to China that she mentioned in the paper, Zheng discusses in her book "New Feminism in China: Young Middle-Class Chinese Women in Shanghai" with a more detailed acknowledgement and description about the cultural migrations and changes of the environment in China, which are closely related to the changes of the economic system and other complicated political factors that differentiate the feminism in China from the west. Cai discuss in their paper (2020) about the changes of psychologies and value of the Chinese people due to the reasons that listed by Zheng.
As a communist country that promotes collectivism and gender equality at the same time, women's individualization and equality seem to be in a perplexed and contradictory situation where it is politically correct to be equal but still with the patriarchal fundamentals as a patriarchal society, and that women are not being independent and free from this first wave of feminism in China but really a process of deinstitutionalization in order to work in the system of the communist economy. There is the tendency that after the open and reform decade in China, women are more independent within the standards of psychological states, values and ideas, but less equal comparing to the times before the open and reform era.

In this study, the individualization across the gender roles in China with its correlation of the cultural migrations due to the reconstruction will be discussed, using the methods of "cross time comparison", "intergenerational comparison", and "historical reconstruction".

\section{METHOD}

This study adopted the experimental method in order to quantitatively assess the level of change in women's personal ambition and family ideals across generations. The study was conducted with the online platform Wenjuanxing, a Chinese platform that combines the functions of Amazon Mechanical Turk and Qualtrics, so that both the study can be created, edited and the participants can be recruited online.

Our study recruited 459 participants, with 143 women and 106 men, ranging from those born in the 70s to those born in the 2000s. There were 32 women born in or before the $60 \mathrm{~s}, 61$ born in the $70 \mathrm{~s}, 53$ born in the $80 \mathrm{~s}, 52$ born in the $90 \mathrm{~s}$, and 51 born in the $2000 \mathrm{~s}$. There were 53 men born in the 70s, 52 born in the $80 \mathrm{~s}, 54$ born in the $90 \mathrm{~s}$, and 51 born in the 2000s.

Half of participants were randomly assigned to the "original gender" condition, and the other half randomly assigned to the "reverse gender" condition. In both conditions, participants read a scenario of marriage and evaluated how reasonable the family role assignment was and the couples' satisfaction for the marriage.

Subsequently, all participants saw a same list of tasks that ranged from making a living and self-development to planning pregnancy and taking care of children. They rated how important are these tasks in their life, how much they should do these tasks, how much they want to do these tasks, how much time they are currently spending on these tasks, and how frequently they engage with these tasks. Specifically, they answered the same set of questions regarding a series of activities, judging from the extent to which they would like to do the given activities in life (on a scale of 0-100), the extent to which they felt like they were supposed to do them (5-point 
Likert scale, from "completely unnecessary" to "must do frequently"), the weight that they assign to the given activities (5-point Likert scale, from "I assign almost no weight to this at all" to "I spend a lot of time on this daily"), the extent to which they valued the given activities (5-point Likert scale, from "I don't value this at all" to "I value this very much"), and the frequency with which they spent time doing the given activities (5-point Likert scale, from "I have never done this" to "I do this almost every day"). The full list of activities can be found in Appendix A.

The data were collected on Wenjuanxing, a Chinese platform that combines the functions of Qualtrics and Amazon Mechanical Turk and then processed in SPSS.

\section{RESULT}

In the marriage scenario, participants deemed the role assignment as more unreasonable when female was the major contributor to the family income and success $(\mathrm{t}=$ $2.29, \mathrm{p}<0.05)$, and there was no significant different between male and female's attitude $(t=1.65, p=0.10)$. Likewise, participants deemed the marriage as more unhappy when female was the major contributor $(\mathrm{t}=3.05$, $\mathrm{p}<0.01$ ), and females were more likely to deem the marriage scenarios as unhappy than males regardless of which gender was the major contributor to income $(\mathrm{t}=$ $2.76, \mathrm{p}<0.01$ ) when there was financial challenges in the marriage scenario. Also, younger participants were significantly more likely to deem the role assignment in marriage scenario with challenges as unreasonable $(t=$ 4.62. $\mathrm{p}<0.001)$ than older participants, regardless of the gender of the major contributor.

There was a significant interaction effect of gender and age on marriage happiness $(\mathrm{F}=3.10, \mathrm{p}<.05)$. While males showed no different in terms of marriage happiness rating across ages $(\mathrm{t}=-1.79, \mathrm{p}=.074)$, younger females were more likely to deem the marriage as unhappy $(\mathrm{t}=$ 4.17, $\mathrm{p}<.001)$.

Finally, we found that, for adult women, years born positively predicted their attitude towards activism on refusing to become pregnant out of family wishes, both in terms of whether they thought they should engage in such activism $(\mathrm{t}=3.70, \mathrm{p}<0.001)$ and whether they thought such behavior were important $(\mathrm{t}=2.00, \mathrm{p}<0.05)$. However, years born predicted neither adult women's actual engagement with activism regarding refusing to become pregnant out of family wishes in daily life $(\mathrm{t}=$ $1.19, \mathrm{p}=0.235)$ nor their time devoted to such activism $(\mathrm{t}=1.62, \mathrm{p}=0.108)$.

\section{DISCUSSION AND CONCLUSION}

Our findings revealed that, while women were explicitly more supportive of activism regarding female rights and independence, such changes in ideology did not impact their daily life and choices in accordance to their claimed ideal, thus making feminist practices a myth. Our results from marriage scenario perception showed the lack of changes in daily feminist engagement might be explained by people's biased perception towards subjective well-being, such as marriage satisfaction and marital role assignment ideals. Thus, ostensible awareness of female rights and independence could hardly translate into daily actions. Our results add the first evidence to our speculation that individualization process could transfer action responsibilities from the collective duties to personal decisions, and such renewed path of patriarchal orders operate through people's subjective perception of personal happiness and marital ideals.

The current study has limitations. First, there might be sampling bias, since all participants were recruited from the Wenjuanxing platform, which demands that these participants were tech-literate, so that participants with lower education background might be unintentionally excluded. Second, those who might feel uncomfortable in participating in the study might give up during the survey process and might not be reflected in the data collected. Finally, there might be other reasons the author did not consider that lead to the result. To address these limitations, future studies could consider collecting data through a quantitative survey conducted by oral survey from the researcher to allow less techliterate people to participate and follow-up semistructured interviews to make sense of the data. Furthermore, to address the potential problem of a biased sample, star random sampling could be applied to collect a representative sample that cover all ages and cultural background.

The current study is the first to show that gender equality awareness has reached many on an explicit, but not an implicit, level. Our findings shed light on important considerations when working with such issues in China and might assist the decision- making process, awareness campaign methods and content, as well as educational matters by relevant parties, including but not limited to governmental departments, NGOs, social organizations and activism groups. Future studies can also consider testing methods that reach implicit perception and attitudes of women to address the lack of awareness and actions on a deeper level.

\section{REFERENCES}

[1] C.A. Bøe, et al, Women and Family in contemporary urban China; Contested female individualization, [D]. The University of Bergen, 2013. DOI:https:/xueshu.baidu.com/usercenter/paper/sho w? paperid $=97938 \mathrm{dabc} 15023658 \mathrm{da} 8 \mathrm{fc} 7 \mathrm{af} 48108 \mathrm{dc}$ $\&$ site $=$ xueshu_se

[2] H.J. Cai, Z.H. Huang, et al, Psychological and Behavioral Changes in Chinese People over Half a 
Century - A Study in Psychological Perspective, [J]. Advances in Psychological Science 2020(10). DOI: https://www.cnki.com.cn/Article/CJFDTotalXLXD202010001.htm

[3] S. H. Schwartz, Are there universal aspects in the structure and contents of human values?, [J]. Journal of social issues,1994.50(4), 19-45. DOI:https://www.scirp.org/reference/ReferencesPa pers.aspx?ReferenceID $=1779648$

[4] W.Z. Song, M.Q. Zhang, The significance and procedure of compiling Chinese personality measurement scale, [J]. Acta Psycholigica Sinica., 1993. 25(4), 400-407.

DOI:http://www.cnki.com.cn/Article/CJFDTotalXLXB199304009.htm

[5] J.R. Zheng, New feminism in China: a qualitative study of fourteen middle class young Chinese women in a key staterun university in Shanghai [D].University of Cambridge, 2012. DOI:https://xueshu.baidu.com/usercenter/paper/sho w? paperid $=628718 \mathrm{cdd} 945 \mathrm{a} 5 \mathrm{e} 7 \mathrm{~b} 1$ edace $1 \mathrm{a} 6308 \mathrm{e} 74$ \&site $=$ xueshu se 